\title{
O PROCESSO DE CONSTRUÇÃO IDENTITÁRIA EM ORGANIZAÇÕES: UMA RELEITURA SOBRE IDENTIDADE
}

\author{
THE PROCESS OF IDENTITY BUILDING IN ORGANIZATIONS: A RE-READING ON IDENTITY \\ EL PROCESO DE CONSTRUCCIÓN IDENTITARIA EN ORGANIZACIONES: UNA RELECTURA SOBRE \\ IDENTIDAD
}

\author{
ANDRÉ FELIPE VIEIRA COLARES \\ Mestre \\ Universidade Federal de Ouro Preto - Brasil \\ colaresafv@gmail.com
}

LUIZ ALEX SILVA SARAIVA

Doutor

Universidade Federal de Minas Gerais - Brasil saraivalas@gmail.com

Submetido em: 21/09/2014

Aprovado em: 06/04/2015

Doi: alcance.v23n4.p568-577

\section{RESUMO}

0 presente caso de ensino busca explorar o estudo das identidades pessoal, social, no trabalho e nas organizações. A identidade pessoal não é constituída apenas pelas escolhas isoladas dos indivíduos, tendo 0 contexto, os agentes sociais e as instituições grande influência neste processo. E é com base na história da vida de Marko Zikyr que este trabalho se desenvolve. Aos seus vinte e poucos anos e homossexual, foi aprovado em um processo seletivo de uma multinacional com escritório na capital mineira. Passados alguns meses nesse novo contexto, Marko pôde começar a constituir-se - sua identidade pessoal começa a criar traços de emancipação. Seu comportamento, modo de se portar e visão do ser gay se modificaram. No entanto, em seu trabalho, a organização não aceitava que empregados em altos cargos fossem homossexuais, de maneira a "preservar" a imagem da empresa. Marko passou então a viver um dilema - "parecer" ou "não parecer" gay, eis a questão - que ia além da sua imagem, e dizia respeito à sua própria identidade. Após diversas situações, para continuar o emprego, Marko aceitou as condições impostas por seu superior, adequando-se à heteronormatividade.

Palavras-chave: Identidade. Indivíduo. Organização.

\section{ABSTRACT}

This teaching case study explores the study of personal, social, work and organizational identities. Identity does not consist only of individuals' isolated choices, but is also heavily influenced by social agents and institutions. This case study developed in this work is the life story Marko Zikyr. In his early twenties, as a homosexual, Zikyr successfully passed a selection process to work for multinational company in the city of Belo Horizonte, the capital of Minas Gerais. After a few months in his new environment, Marko started to constitute himself - his personal identity begun to take on traces of emancipation. His behavior, his way of being, and his view of what it means to be a homosexual began to change. However, the company he worked did not accept "gay" employees in top positions. Through this policy, it believed it was "protecting" its business image. So Marko had a dilemma whether to "look gay" or not, that was the question - which went beyond his image, raising issues of his identity. After going through several situations, in order to keep his job Marko agreed to accept the conditions imposed by his superior, adapting himself to heteronormativity. 
Keywords: Identity. Individual. Organization.

\section{RESUMEN}

El presente caso de enseñanza tiene el propósito de explotar el estudio de las identidades personal y social en el trabajo y en las organizaciones. La identidad personal no está constituida solamente por las elecciones aisladas de los individuos, puesto que el contexto, los agentes sociales y las instituciones ejercen gran influencia en este proceso. Este trabajo se desarrolla en base a la historia de la vida de Marko Zikyr. Con poco más de veinte años y homosexual, fue aprobado en un proceso selectivo de una multinacional con oficinas en la capital de Minas Gerais. Pasados algunos meses en ese nuevo contexto, Marko pudo empezar a constituirse y su identidad personal comenzó a mostrar rasgos de emancipación. Su comportamiento, modo de ser y visión del ser gay se modificaron. Sin embargo, en su trabajo la organización no aceptaba que los empleados que desempeñaban altos cargos fuesen homosexuales, para "preservar" la imagen de la empresa. Marko pasó entonces a vivir un dilema - "parecer" o "no parecer" gay, esa es la cuestión - que iba más allá de su imagen, y tenía que ver con su propia identidad. Para continuar en el empleo, después de diversas situaciones, Marko aceptó las condiciones impuestas por su superior, adecuándose a la heteronormatividad.

Palabras clave: Identidad. Individuo. Organización.

\section{INTRODUÇÃO}

A identidade pessoal não é constituída apenas pelas escolhas isoladas dos indivíduos, tendo 0 contexto, os agentes sociais e as instituições grande influência neste processo. É preciso, então, refletir sobre como se dá o processo de construção identitária individual e a influência das organizações nessa constituição.

É a partir da necessidade de compreender o quanto o comportamento dos indivíduos é influenciado na construção de suas identidades que este trabalho ganha relevância. $O$ enfoque do caso de um indivíduo homossexual é interessante por conta de sua posição anti-hegemônica em relação aos modelos ideais de comportamento e imagem.

Se aos indivíduos heterossexuais a constituição identitária já é um processo difícil devido a toda uma adequação social e às ideias de "certo" e "correto", para os homossexuais este processo já tem no berço uma dificuldade: ser descontruído diariamente, por vezes, em seu próprio núcleo familiar e logo mais, na escola, no grupo social de referência e nas organizações nas quais vier trabalhar.

Daí a necessidade de se discutir e refletir sobre o processo de constituição identitária e, em se tratando de nossa área, vinculá-lo ao ambiente organizacional. É necessário refletir sobre as práticas adotadas nas organizações e no processo de objetificação dos sujeitos, transformados em mero componente organizacional, fantoches de um teatro de enredo criado pelos gestores e pelo capital.

São esses os pressupostos desta discussão. A identidade aqui trabalhada será revelada por diversas perspectivas desenvolvidas nos Estudos Organizacionais, o que é necessário, tendo em vista de que se trata de um conceito complexo demais para se adequar a modelos, sejam teóricos ou organizacionais.

\section{DESCRIÇÃO DO CASO}

Marko Zikyr se tornou o mais novo morador de Belo Horizonte em 2014. Havia sido aprovado em um processo seletivo para cargo de analista de marketing de uma multinacional com escritório na capital mineira. Apesar de ser do interior do estado e ter sentido algumas dificuldades no processo seletivo, foi selecionado e ficou imerso durante duas semanas na Universidade Multinacional X; espaço onde ocorriam a apresentação da empresa (a doutrinação,) os treinamentos e a capacitação dos novos empregados.

Recém-formado em Administração e com pouco mais de vinte anos, Marko descobriu-se gay aos quatorze anos. Oriundo de uma família tradicional de uma cidade de médio porte, percebia em sua família traços de preconceito e discriminação, principalmente no que concernia às falas e aos discursos de seu pai. Era comum em reuniões de família ou quando do assunto em foco o pai soltar frases como "se eu tiver um filho gay eu mato"; "gente assim precisa é de couro, que aí, conserta"; "eu expulso de casa se descobrir que tenho um 
filho assim", entre outros, fazendo com que Marko se reprimisse cada vez mais, principalmente no que se referia à sua sexualidade.

Aos dezesseis anos seus pais descobriram que Marko era gay e apresentaram forte repúdio ao que para eles era considerada uma escolha, uma opção sexual. A partir de então, tentaram "converter" Marko de todas as formas. $O$ cerceamento e controle de seus atos e atividades, buscando vigiar para onde ia e com quem saía, só reforçavam as formas de repressão. Eles acreditavam que, ao inibi-lo, evitariam que Marko se "firmasse" homossexual.

Aos dezenove anos Marko se afirma como homossexual. A reação do pai foi a de romper relações com ele, possivelmente acreditando que, ao boicotar seu estilo de vida e usando esse ato como retaliação, Marko voltaria atrás. Ainda que sua mãe aceitasse de forma melhor essa situação, Marko ainda se sentia preso dentro de sua cidade, já que se responsabilizava por qualquer boato que "sujasse" o nome de sua família - como seu pai havia sugerido que aconteceria caso outras pessoas descobrissem sua homossexualidade.

Ainda que agora sentisse maior liberdade, já que não havia nada a esconder de sua família, Marko ainda se escondia da sociedade. Foram cinco anos se escondendo de seus pais e sete anos se escondendo da sociedade, uma vez que ser gay significava promiscuidade, vadiagem, sexo e AIDS. Mas, mais do que isso, Marko se escondia de si mesmo, uma vez que não era como gostaria de ser; em sua essência, era reflexo do que o que era tido como aceitável pela sociedade.

Aos vinte e um anos, ao passar no processo seletivo, Marko mudou-se para a capital do estado onde residia. Era como se tivesse ganho uma carta de alforria, até certo ponto. 0 processo de imersão dentro da Universidade Multinacional $X$ o fez ver que, ainda que estivesse em uma cidade maior e que suas expectativas fossem de pessoas com "cabeças mais abertas", a empresa para a qual ele agora trabalhava cultuava determinadas condutas e posturas de seus profissionais: a imagem estereotipada de "homem", assim, deveria ser mantida.

Os primeiros meses ainda se pareciam muito com os últimos anos em sua vida. Marko ainda se sentia repreendido, mas agora nem tanto pela sociedade, mas pelas próprias construções sociais que trazia consigo. Apresentava certo receio quanto ao estereótipo de "homem", e por isso vivia tenso, tentando a todo momento se "controlar". Ele escondia de seus superiores a sua orientação sexual com medo do posicionamento que poderiam ter. Com o passar dos meses, Marko começou a se dar conta de quem realmente queria ser. Seu comportamento, modo de se portar e visão de ser gay começavam a se modificar.

Em uma de suas saídas pela nova cidade, descobriu uma região gay friendly'. Embora ele soubesse que na nova cidade os gays se expunham mais e sem formas explícitas de repúdio por ser quem eram, naquela área Marko se encontrou. Era uma área boêmia, com bares, boates e quarteirões fechados em que gays, lésbicas e simpatizantes frequentavam e podiam ser exercer sua sociabilidade com naturalidade, com ampliação do que era tomado como "socialmente normal".

A partir dessa ocasião e de visitas recorrentes a esse espaço, Marko passou a se aceitar de forma melhor, a se sentir mais livre para se expressar e ser quem sempre quis ser: o verdadeiro Marko. Começou então um processo de se "libertar": comprou roupas mais coloridas, calças mais justas; passou a se cuidar mais, agora se depilava, inclusive. Fugia ao padrão heteronormativo que antes the era imposto na antiga cidade. Chegou a assumir para seus colegas de moradia sobre sua homossexualidade. No entanto, em seu trabalho algumas questões estavam ficando críticas.

A mudança em suas vestimentas e a adoção por roupas com cores mais vivas fizeram despertar dentro da Multinacional $\mathrm{X}$ a ideia de que Marko era homossexual, e as conversas de corredor começavam a anunciar os possíveis riscos desse comportamento. Suellen, uma de suas colegas de trabalho, chegou a chamar Marko para conversar e lhe dar alguns conselhos: "Você pode ser gay, a empresa não importa, desde que você não pareça", uma frase amiga que traduzia o posicionamento da organização.

Marko passou então a viver uma dicotomia: "parecer" ou "não parecer" gay? Eis a questão. Havia demorado muito para que ele pudesse viver como realmente queria, sem sofrer coerção social ou de familiares, e agora se via coagido pela própria organização que the abriu as portas à nova realidade. Marko acabou optando por comprar novas roupas e se adequar ao modelo padrão de "homem" da organização.

\footnotetext{
1 Áreas frequentadas em sua maioria por homossexuais e simpatizantes nas quais há expressão pública de homoafetividade.
}

Revista Alcance - Eletrônica - vol. 23 - n. 4 - out./dez. 2016 
O dia a dia na organização voltou ao normal. Não mais era visto como o "tomate podre" da safra. Em uma das reuniões individuais, seu chefe chegou lhe parabenizar, não só pelos resultados, "Marko, você tem se saído muito bem, o seu setor apresenta saldo positivo e mais positivo ainda está sua imagem após essa repaginada que você deu, continue assim e em breve receberá uma promoção".

Ainda que vivendo duas vidas, Marko via como viável a possibilidade de mantê-las, até a ocorrência de um fato, após sair com amigos para uma boate GLS. Quando deixava a boate, deparou-se com um bar onde se encontrava, em um jantar, a alta cúpula da Multinacional X. Este fato acabou fazendo com que um de seus superiores se levantasse da mesa e fosse em sua direção, onde logo avisou, "Marko, amanhã às 14 horas em minha sala, precisamos conversar sobre seu comportamento e vida social, a empresa não pode pagar a conta".

No dia seguinte, no horário marcado pelo seu superior, Marko se apresentou ao seu superior. Em poucas palavras e quase sem diálogo, ele ouviu de seu chefe: "Marko, o tipo de situação que presenciei ontem não pode acontecer, nem deve se repetir. É uma afronta à imagem da empresa, uma multinacional como nós somos, ter um analista de marketing, que é quem faz a 'cara' da empresa, homossexual. E o pior, que seja homossexual, não cabe a mim julgar certo ou errado, não tenho e a empresa também não tem preconceito, mas não se pode viver por aí bebendo e saindo como uma bicha louca pela cidade. Pega mal pra você, para a empresa e, pior, pega mal pra mim, mostra ingerência. Não posso aceitar isso. Há pouco o elogiava pela sua conduta, agora estou aqui lhe advertindo. E será a última vez. Ou você se adequa ao que aqui lhe digo e posso Ihe dar uma promoção, como recompensa, como agrado ou não se adequa e serei obrigado a demiti-lo. Deixarei que pense e veja o que the é melhor, e não se esqueça de ponderar o plano de carreira que tem pela frente e 0 quanto foi difícil chegar até aqui".

Marko saiu da sala de seu superior indeciso. Estava na mesma situação em que viveu tempos atrás na sua cidade: deveria esconder quem ele era se quisesse continuar na empresa. $O$ processo seletivo pelo qual passou, a ideia de emancipação social e "subida" na vida, saindo de sua cidade natal e indo para capital só o faziam pensar na necessidade de garantir aquele emprego. Lembrava-se também de ser ele mesmo, e de como deixou para trás um círculo social que o fazia mal por conta da sua sexualidade. No entanto, esta última superação agora esbarrava no contexto profissional em que se encontrava e que afetava diretamente seu estilo de vida e seu jeito de ser.

Após muito refletir, Marko decidiu continuar no emprego e aceitar as condições impostas por seu superior, isto é, se adequaria à heteronormatividade. Esperava, rapidamente, conseguir outra boa oportunidade profissional, para que pudesse conciliar o profissional e o pessoal. Sabia que a situação atual provavelmente seria passageira, mas ficou imaginando quantos homossexuais fingem o ideal de macho no seu cotidiano profissional para procurar manter seus empregos e suas carreiras. 


\section{NOTAS DE ENSINO}

\section{OBJETIVOS DE APRENDIZAGEM}

O caso relatado busca trazer à discussão a questão do desenvolvimento identitário dos indivíduos, sua relação com a identidade social, a identidade no trabalho e a identidade organizacional. Essa discussão é importante devido às diversas relações estabelecidas entre os diversos atores sociais e o nível de influência que cada um deles tem na construção da identidade individual, em especial, a organização. Em conexão com essa discussão, é possível abordar o processo de emancipação identitária dos indivíduos ao se encontrarem em um novo grupo social; e também a repressão a este processo. No caso específico, abre-se a discussão para os estereótipos sociais acerca do ser homem, das orientações sexuais, e o consequente posicionamento que homossexuais, por vezes, são obrigados a adotar, caso queiram permanecer ou avançar na carreira profissional. 0 caso pode ser utilizado em disciplinas ligadas a práticas de gestão de pessoas, em discussões específicas ligadas à inclusão de minorias e à diversidade organizacional e outras que abordem as possibilidades de diferenças entre os indivíduos e os seus desdobramentos sobre a organização.

\section{FONTES DOS DADOS}

Este relato de caso foi baseado em uma história verídica, ocorrida com um acadêmico de pós-graduação da Universidade Federal de Minas Gerais. Os nomes dos personagens e das organizações foram preservados, de forma a preservar os envolvidos, tendo-lhes sido atribuídos nomes fictícios. Os dados foram levantados por meio de entrevista junto ao acadêmico e consequentes conversas, possibilitando um acompanhamento posterior da história.

\section{QUESTÕES PARA DISCUSSÃO}

1. De que forma se constitui a identidade pessoal? E qual o nível de influência de atores externos ao indivíduo no processo de sua formação identitária?

2. É possível conceber identidade pessoal e social como constituídas por meio de um processo dialético e contínuo?

3. As organizações têm influência no desenvolvimento identitário de seus empregados? É possível pensar na identidade organizacional como diferente da imagem da organização?

4. É recorrente, em processos de seleção e recrutamento, as organizações se apegarem a modelos ideais de funcionários?

5. Identifique se no caso de ensino é observada a existência de traços de preconceito, social e/ou organizacional.

6. É possível afirmar que a questão do poder é determinante para a adequação social dos indivíduos a determinados padrões, tidos como aceitos?

7. Existe um limite de intervenção da organização quanto às questões pessoais dos seus empregados? Se sim, qual seria este limite?

8. Reflita acerca da realidade da constituição identitária de homossexuais em situações como a apresentada. 


\section{ANÁLISE DO CASO E REVISÃO DE LITERATURA}

A condução da análise e a discussão do caso de ensino podem seguir o seguinte roteiro de temáticas: i) identidade pessoal, identidade social, identidade no trabalho e a identidade organizacional - buscando discutir 0 que é identidade, seu processo de formação e os modos como estas se constituem e se autoinfluenciam e; ii) a construção social da identidade de homossexuais - o processo de socialização, coerção social e padrões sociais impostos.

É necessário, inicialmente, desenvolver a discussão acerca da identidade sob a ótica de Machado (2003), que a apresenta em quatro níveis: i) identidade pessoal; ii) identidade social; iii) identidade no trabalho e; iv) identidade organizacional. Neste trabalho, buscou-se usar desta classificação como base para discussão por acreditar que entre as diversas perspectivas de estudo sobre identidade desenvolvidas está é a que mais atende aos objetivos deste trabalho.

A identidade pessoal converge com o conceito de identidade como si mesmo e como construção social trabalhado por Bauer (2004). A identidade pessoal tem foco na constituição das identidades individuais, pensada por meio da construção social. É mediante as relações sociais, os fluxos e as trocas sociais que o indivíduo busca identificar questões que lhe são interessantes e aquelas que ele tende a refutar. Trata-se da construção de uma unidade individual e subjetiva de identidade (MACHADO, 2003).

A identidade social, por outro lado, está ligada aos grupos sociais, sendo constituída em âmbito coletivo. Por se tratar de uma coletividade, essa identidade se estabelece a partir dos processos de identificação e de negação dos indivíduos que, assim, se agregam por semelhanças percebidas (MACHADO, 2003). Esse nível de identidade se aproxima das discussões de Bauer (2004) sobre identidade como diferença e como processo de identificação, pois é por meio da aproximação dos indivíduos, constituindo grupos reconhecidos socialmente, que a identidade social se firma.

A identidade no trabalho se vincula ao espaço organizacional em que o indivíduo está inserido. É por meio das relações de poder ali estabelecidas, da hierarquização organizacional e das pretensões quanto à carreira e à ascensão que a identidade pessoal tende a ser ajustada ao contexto em que o indivíduo se insere. "O tipo de relações de trabalho e de poder que é mantido no universo empresarial influencia sobremaneira a construção de identidades" (MACHADO, 2003, p. 58).

A identidade organizacional, diferentemente da identidade no trabalho, está relacionada à identidade da organização, constituída e compartilhada pelos sujeitos que dela fazem parte. É construída com base nos valores e nas crenças compartilhados neste espaço (MACHADO, 2003), sendo também reconhecidos e identificados por seus membros. Essa lógica de compartilhamento de algo central e comum à organização tende a influenciar, em diversos níveis, a constituição dos sujeitos e a formação de suas identidades. Para além do âmbito familiar, da escola e dos grupos sociais com os quais se identifica, a organização também é um espaço/instituição de socialização e que exerce forte influência na formação identitária individual.

Essas quatro perspectivas apresentadas por Machado (2003) possibilitam entender, em um contexto macro de relações, como ocorre a constituição identitária dos indivíduos. Ainda que os estudos sobre identidade a categorizem de diversas formas, os argumentos apresentados trazem pontos interessantes para este caso, uma vez que também dialogam com outras abordagens como a de Carrieri, Paula e Davel (2008). É percebendo a ideia de construção social da identidade e que esta construção não se dá isoladamente dos diversos atores sociais que se pode compreender em um contexto organizacional a importância da organização.

Como apontado por Borges e Medeiros (2011, p. 134), a identidade pode ser considerada ainda como "um objeto, com cor, forma, função e outras características que podem variar em grau de utilidade para as organizações", tornando-se um ativo, um recurso manipulável, social e organizacionalmente. Ceccarelli (2012, p. 106) complementa que "por falta de identidade, somos condenados à identificação!". E, portanto, constitui-se um processo libertador e limitador, o qual oscila neste continuum de acordo com o modelo de identificação adotado, sendo considerado um processo inconsciente que busca, por meio de uma dinâmica própria, constituir o Eu baseado em diversas identificações que se faz do outrem. É "o resultado do encontro do Eu em formação com outros Eus significativos que marcaram a vida através de gerações" (CECCARELLI, 2012, p. 106).

Dentre a conceituação de identidade, Carrieri, Paula e Davel (2008), discutem que a identidade relacional está baseada na relação que os indivíduos mantêm com a estrutura organizacional em que se inserem. A constituição da identidade, neste tipo de relação, é diretamente afetada pela organização e por suas diversas categorias/estruturas - como grupos de trabalho, departamentos, grupos de mesma idade. Dessa 
forma, os autores defendem que os indivíduos mantêm relação de interação pessoal e simbólica com os demais, em um contínuo processo de formação e reconhecimento de identidades.

Em específico, a identidade sexual, uma das facetas da identidade pessoal, perpassa pela influência de diversos elementos constituídos e reproduzidos no imaginário social. Nesse sentido, Ceccarelli (2012) aponta que a sexualidade humana é constituída por meio do sexo anatômico do recém-nascido - homem ou mulher; do lugar que ele ocupa no imaginário dos pais - a construção que se faz sobre o que é ser filho homem e o que é ser filha mulher; da dinâmica libidinal - e os pressupostos criados sobre o que deve atrair o indivíduo é o sexo oposto e, das representações sociais do masculino e do feminino, que partem de modelos e padrões tidos como aceitáveis.

A discussão alcança, então, o ponto-chave do caso que é o sujeito homossexual. Durante seu processo de constituição identitária tem de lidar com o processo de coming out, ou assumir-se, tido como uma, das duas grandes experiências que a maioria dos homossexuais compartilham (SCHULMAN, 2010; CAPRONI NETO, SARAIVA, BICALHO, 2014). Este primeiro processo tem como base a interrogação pessoal acerca do "que sou" que vai de encontro à expectativa social do "o que deveria ser" - não havendo qualquer processo similar na vida heterossexual.

Caproni Neto, Saravai e Bicalho (2014) exploram o processo de coming out como um rito relevante no processo de construção da identidade homossexual. O famoso "sair do armário" tende a se refletir diretamente no desenvolvimento e na aceitação desta identidade como um autoconceito, uma aceitação de si, bem como um momento de demarcação no contexto social, ainda que estigmatizado por seu círculo social.

Schulman (2010) aponta que a segunda experiência, a qual terá um maior enfoque neste trabalho, é a de que, em algum momento em suas vidas, os homossexuais são/serão inferiorizados (por suas famílias, social e profissionalmente), tendo como principal fator motivador a homossexualidade. Essa segunda experiência é institucionalizada, socialmente, por um sistema que é diariamente replicado, e por estruturas sociais dominantes, por meio das quais definem o que é ser gay e como deve viver, um processo semelhante a um jogo de espelhos, no qual o próprio sistema realimenta as bases para esta situação.

A construção desse modo de viver gay vai de encontro à socialização da diferença entre ser homem e o ser mulher, dentro de um sistema que define o que é o masculino, o que "ele" tem que ser e fazer (DA MOTA, 2012). Ser gay significa ter de se "encaixar" entre ser fisicamente homem, e ser socialmente considerado um não homem, o que influencia diretamente a construção identitária. E é por meio da definição de determinados atos como pecado que a sociedade busca exercer o disciplinamento baseado na heteronormatividade, atentando à identidade homossexual os primeiros passos da educação dos meninos.

O processo de construção dos modos ideais de vida tende a influenciar diretamente a construção identitária dos sujeitos, ainda que eles eventualmente não compartilhem tais modos. É por meio da construção social destes modos e da produção discursiva que se dá no âmbito social que o indivíduo se reprime, atrelando a si uma identidade social que tende a ser diferente da identidade pessoal desejada.

Neste sentido, quando Van Riel (1995) discute quatro tipos de identidade: percebida, projetada, desejada e aplicada, ele abrange a questão da problemática identitária do homossexual aqui estudado. 0 indivíduo tende a oscilar seu comportamento entre a identidade aplicada (o que ele realmente é) e a identidade projetada (como ele quer ser visto), subvertendo sua própria identidade para ser aceito e reconhecido em seu círculo social. É interessante ressaltar que, mediante um processo de coerção social, a maioria dos homossexuais tende a ter uma identidade desejada próxima da concebida por seu meio social como "adequada" e bem diferente do que seria sua identidade aplicada. Em outras palavras, é preciso submeter-se para ser aceito.

Schulman (2010), ao tratar a homofobia familiar, busca discutir suas especificidades e dimensões, que se apresentam bem amplas. Neste trabalho, apropriou-se da discussão para apontar as formas e como se desenvolve a homofobia nas organizações, que pode variar desde pequenos desrespeitos, e graus variados de exclusão, até processos de retaliação organizacional, algo que pode se tornar uma opressão dolorosa e determinante na vida da pessoa gay.

Para Espejo (2011), as escolas, sendo organizações, trazem consigo um histórico de produtoras e reprodutoras de diferenças, desigualdades e distinções, usando diversos mecanismos e artifícios para classificar, hierarquizar e ordenar $\mathrm{O}$ ambiente e os sujeitos. $\mathrm{O}$ autor aponta que, servindo-se de símbolos e códigos, buscam construir o que "se pode" e o que "não se pode", de forma a apresentarem modelos nos quais os indivíduos podem se projetar. 
Espejo (2011) se respalda em Foucault (1997) para discutir que, entre as relações de poder mantidas dentro das organizações, estas tomam os indivíduos como objetos e como instrumentos. Este posicionamento Ihes permite "fabricá-los" de forma sutil, quase imperceptível, corroborando com o já apresentado, processo passivo de constituição identitária. É neste nível que a identidade organizacional tende a afetar a identidade pessoal - as práticas e os discursos cultivados no âmbito organizacional afetam diretamente os indivíduos, que estão sempre em busca de adequação aos parâmetros organizacionais.

Essa fabricação do indivíduo torna-se mais acentuada no caso dos homossexuais, uma vez que atinge diretamente a questão da sexualidade - não havendo paralelo para os heterossexuais. É necessário reforçar a "falseabilidade" desta construção, pois "os discursos sobre a sexualidade são invenções tributárias do momento sócio-histórico da cultura na qual emergem" (CECCARELLI, 2012, p. 106). Isto é, não refletem a verdade vivida pelo sujeito, pois buscam reforçar as necessidades, as situações e as práticas às formas de viver socialmente valorizadas. Dessa forma:

Basados en la presunción universal de la heterosexualidad y el consecuente régimen de privilegios, se establecen puniciones sociales para quien se aparta de esta norma. Así el heterosexismo se constituye en un prejuicio institucionalizado en contra de la homosexualidad, mantenido por el consenso social que sanciona y promueve esta ideología. (ESPEJO, 2011 - p. 52).

Dessa forma, as organizações fazem uso dos modelos heterossexuais para desenvolver, organizacionalmente, a identidade projetada de seus empregados. Segundo Carrieri, Paula e Darvel (2008), esta pode ser definida como aquela que é elaborada, desenvolvida e divulgada pela alta gerência que, se utilizando dos canais de comunicação e de técnicas de gerenciamento, busca criar a identidade coletiva da organização. Baseando-se, em sua maioria, na crença da superioridade de um modelo (heterossexual) sobre todos os outros e seu consequente direito de dominação (LORDE, 1985).

Da Mota (2012) discorre que lidar com tal norma/modelo heterossexual é um peso para aquele que 0 faz. Se por um lado a ela se submete, o sujeito termina por reforçar o padrão de estigma aos homossexuais; se busca se impor e se sobressair em relação a ele, buscando garantir um olhar mais positivo de si, de torna "visível", o que não é aceitável. Irigaray, Saraiva e Carrieri (2010) apontaram que há evidências que exposição e identificação de um indivíduo enquanto homossexual pode comprometer seu progresso profissional no ambiente corporativo. E que, de forma a entrarem no "jogo", muitos homossexuais se veem obrigados a manter um contínuo estado de alerta comportamental, vigiando-se acerca de postura e atitudes, limitando-se àquelas consideradas positivas.

Os homossexuais, ao se submeterem à norma, conseguem maior visibilidade profissional, mas comprometem seu desenvolvimento individual, sua emancipação identitária e sexual. Tal afirmação é corroborada por Carrieri (2001), ao afirmar que, ao buscarem interagir com e no ambiente no qual estão inseridos, os indivíduos são induzidos (consciente ou inconscientemente) a introjetarem signos, valores e comportamentos. Este processo tem como base a busca por afirmação naquele contexto, mas tende a confirmar ou reforçar uma identidade que pressupõe ser a pretendida pela organização e não a desejada pelo indivíduo.

Ghadiri e Davel (2006) ratificam tal posicionamento, ao considerarem a identidade inserida em um processo espiral (percepção, evocação e reconstrução) que se desenvolve por meio dos relacionamentos diários dentro e fora das organizações. A partir daí, é possivel perceber que a constituição da identidade individual é sempre afetada pela identidade de quem percebe, daqueles com que ele se relaciona. Sendo assim, Borges e Medeiros (2011) verificaram em seus estudos que as organizações buscam, por meio da influência nas ações individuais e coletivas, tornar possível a gestão produtiva da identidade. 


\section{REFERÊNCIAS}

BORGES, J. F.; MEDEIROS, C. R. O. "Aprecie com moderação": a identidade da organização como drama e atos de performance. Revista de Administração de Empresas, São Paulo, v. 51, n. 2, p. 132-142, mar./abr. 2011.

CAPRONI NETO, H. L.; SARAIVA, L. A. S.; BICALHO, R. A. Diversidade sexual nas organizações: um estudo sobre coming out. Revista Pensamento Contemporâneo em Administração, Niterói, v. 8, n. 1, p. 86-103, jan./mar. 2014.

CARRIERI, A. P. 0 fim do "mundo Telemig": a transformação das significações culturais em uma empresa de telecomunicações. 2001. 326 f. Tese (Doutorado em Administração) - Faculdade de Ciências Econômicas, Universidade Federal de Minas Gerais, Belo Horizonte, 2001.

CARRIERI, A. P; PAULA, A. P. P.; DAVEL, E. Identidade nas organizações: múltipla? Fluida? Autônoma? Organizações \& Sociedade, Salvador, v. 15, n. 45, p, 127-144, abr.jun. 2008.

CECCARELLI, P. R. $O$ que as homossexualidades têm a dizer à psicanálise (e aos psicanalistas). Bagoas: Revista de Estudos Gays, Natal, n. 8, p. 103-123, 2012.

DA MOTA, M. P. A construção da homossexualidade no curso da vida a partir da lembrança de gays velhos. Bagoas: Revista de Estudos Gays, Natal, n. 7, p. 199-222, 2012.

ESPEJO, J. C. "Coming out" en la escuela. Bagoas: Revista de Estudos Gays, Natal, n. 6, p. 49-68, 2011.

FOUCAULT, M. Vigiar e punir: história da violência nas prisões. 41. ed. Petrópolis: Vozes, 2011.

GHADIRI, D. P.; DAVEL, E. Do sólido ao fluido: contradição organizacional e paradoxo na reconstrução de identidade. Revista de Administração de Empresas - RAE-eletrônica, São Paulo, v. 5, n. 1, jan./jun. 2006.

IRIGARAY, H. A. R.; SARAIVA, L. A. S.; CARRIERI, A. P. Humor e discriminação por orientação sexual no ambiente organizacional. Revista de Administração Contemporânea, Curitiba, v. 14, n. 5, p. 890-906, set./out. 2010.

LORDE, A. I am your sister: black women organizing across sexualties. Latham: Kitchen Table Press/Women of Color Press, 1985.

MACHADO, H. V. A identidade e o contexto organizacional: perspectivas de análise. Revista de Administração Contemporânea, Curitiba, v. 7, n. spe, p. 51-73, jan. 2003.

SARAIVA, L. A. S.; IRIGARAY, H. A. R. Políticas de diversidade nas organizações: uma questão de discurso? Revista de Administração de Empresas, São Paulo, v. 49, n. 3, p. 337-348, jul./set. 2009.

SCHULMAN, S. Homofobia familiar: uma experiência em busca de reconhecimento. Bagoas: Revista de Estudos Gays, Natal, n. 5, p. 67-78, 2010.

VAN RIEL, C. B. M. Principles of corporate communication. London: Academic Service and Prentice Hall, 1995.

\section{BIBLIOGRAFIAS RECOMENDADAS}

ALBERT, S.; WHETTEN, D. Organizational identity. In: CUMMINGS, L. L.; STAW, B. M. (Ed.). Research in organizational behavior. Greenwich: JAI Press, 1985. p. 179-229.

CALDAS, M. P.; WOOD JR., T. Identidade organizacional. Revista de Administração de Empresas, São Paulo, v. 37, n. 1, p. 6-17, jan./mar. 1997.

CARRIERI, A. P.; SARAIVA, L. A. S.; ENOQUE, A. G.; GANDOLFI, P. E. (Org.). Identidade nas organizações. Curitiba: Juruá, 2010.

DESCHAMPS, Jean Claude; MOLINER, Pascal. A identidade em psicologia social: dos processos identitários às representações sociais. Tradução de Lúcia M. Endlich Orth. Petrópolis: Vozes, 2009.

GERGEN, K. J. The saturated self: dilemmas of identity in contemporary life. New York: Basic Books, 1991.

IÑIGUEZ, L. Identidad: de lo personal a lo social. Um recorrido conceptual. IN: CRESPO, E. (Ed.). La Constitución social de la subjetividade (p.209-225). Madrid: Catarata. 
NKOMO, S. M.; COX JUNIOR, T. Diverse identities in organizational. In: CLEGG, S. R.; HARDY, C.; NORD, W. (Ed.) Handbook of organization studies. London: Sage, 1996. p.338-356. 